\title{
O USO DAS TECNOLOGIAS DE INFORMAÇÃO E COMUNICAÇÃO NA AGRICULTURA FAMILIAR: UM CAMINHO PARA A SUSTENTABILIDADE
}

\author{
Juliana Correa Bernardes ${ }^{1}$ \\ Silvia Cristina Vieira ${ }^{2}$ \\ Eduardo Baio Bonfim ${ }^{3}$
}

Ricardo César Gonçalves Sant'Ana ${ }^{4}$

\begin{abstract}
RESUMO
Apesar do uso das Tecnologias de Informação e Comunicação (TIC) não fazer parte do dia a dia da totalidade dos produtores rurais pertencentes à Associação de Bananicultores de Tupã, elevada parcela destes agricultores familiares notam a importância do acesso a estas informações para a gestão sustentável da propriedade. O objetivo deste trabalho, foi analisar como o acesso às TIC utilizada pelos agricultores familiares da Associação dos Bananicultores de Tupã pode auxiliar na sustentabilidade da propriedade rural. Utilizou-se a metodologia do estudo de caso, que segue como estratégia na pesquisa para esclarecer os motivos pelos quais as decisões foram tomadas. Concluiu-se que o acesso às TIC se demonstrou um instrumento eficiente, tendo nas informações e trocas dialógicas no ambiente virtual, um caminho para o avanço das práticas do desenvolvimento e manutenção da sustentabilidade em suas propriedades rurais.
\end{abstract}

Palavras-chave: Agricultura Familiar. Tecnologia de Informação e Comunicação. Sustentabilidade.

\section{THE USE OF INFORMATION AND COMMUNICATION TECHNOLOGY IN THE FAMILY FARMING: A PATH TO SUSTAINABILITY}

\footnotetext{
1 Aluna Especial da Disciplina Sociedade e Natureza do Mestrado em Agronegócio e Desenvolvimento pela UNESP/Campus de Tupã. Graduada em Medicina Veterinária pelas Faculdades Adamantinenses Integradas. Membro do projeto CoDAF e grupo PGEA. bernardescj@gmail.com

${ }^{2}$ Mestranda em agronegócio e desenvolvimento, especialista em gestão do agronegócio e HIPOA/Vigilância sanitária de alimentos, graduada em medicina veterinária. Membro do Projeto de Extensão CoDAF e dos Grupos de Pesquisa CEPEAGRO e PGEA. UNESP Campus de Tupã. E-mail.tinavieiragomes@hotmail.com.br

3 Graduando em Administração pela Universidade Estadual Paulista Júlio de Mesquita Filho (UNESP Tupã). Graduado em Mecanização em Agricultura de Precisão pela FATEC Shunji Nihimura de Pompeia. Membro do projeto CoDAF. eduardo.baiobonfim@gmail.com

${ }^{4}$ Doutor em Ciência da Informação. Curso de Administração - UNESP - Campus de Tupã; Programa de Pós-Graduação em Ciência da Informação - UNESP - Campus de Marília. ricardosantana@marilia.unesp.br
} 


\begin{abstract}
Despite the use of Information and Communication Technologies (ICT) do not be part of everyday life of all farmers belonging to the Association of banana growers of Tupã, a big part of these farmers note the importance of the access to this information for the sustainable management of the property. The objective of this work was to analyze how the access to ICT used by the family farmers belonging to the Association of banana growers of Tupã can help the sustainability of rural property. We used the methodology of the case study, which remains as strategy in the research to clarify the reasons why decisions were made. It was concluded that the access of ICTs have been shown to be efficient instruments with the information and dialogic exchanges in the virtual environment, a path for advancing the development and maintenance of sustainable practices on their farms.
\end{abstract}

Key words: Family Farming. Information and Communication Technologies. Sustainability.

\title{
EL USO DE TECNOLOGÍAS DE INFORMACIÓN Y COMUNICACIÓN EN LA AGRICULTURA FAMILIAR: UN CAMINO HACIA LA SOSTENIBILIDAD
}

\section{RESUMEN}

Aunque el uso de las Tecnologías de Información y Comunicación (TIC) no es parte de la vida cotidiana de todos los agricultores que pertenecen a la Asociación de productores de banano de Tupã, gran parte de estos agricultores se dan cuenta de la importancia del acceso a estas informaciones para la gestión sostenible de las propiedades. El objetivo de este trabajo fue analizar cómo el acceso a uso de las TIC por los agricultores de la Asociación de productores de banano de Tupa puede ayudar en la sostenibilidad de la propiedad rural. Se utilizó la metodología del estudio de caso, que sigue como estrategia en la investigación para aclarar las razones por las cuales se tomaron las decisiones. Se concluyó que el acceso a las TIC se há demostrado uma herramienta eficaz, tener la información y los intercambios dialógicos en el entorno virtual, una manera de avanzar en el desarrollo y mantenimiento de las prácticas sostenibles en sus fincas.

Palabras clave: Agricultura Familiar. Tecnologías de la Información y la Comunicación. Sostenibilidad.

\section{INTRODUÇÃO}

$\mathrm{Na}$ busca para vencer as barreiras da construção das competências digitais no meio rural, em especial no cenário da agricultura familiar, esta pesquisa estuda o uso das Tecnologias da Informação e Comunicação - TIC aliadas a um processo de comunicação eficiente para atender as necessidades de uma comunidade rural, pertente a Associação dos Bananicultores de Tupã SP, proporcionando o desenvolvimento rural sustentável. 
Nesse sentido, este estudo parte do princípio de que o conhecimento gerado por meio das TIC pode resultar em ações transformadoras ou apontar caminhos para o desenvolvimento sustentável do campo.

Navarro (2011) aponta que as primeiras expressões de desenvolvimento rural estavam pautadas nas condições de produtividade agrícola e ou agropecuária. Suas características, estritamente voltadas à produtividade, ainda possuíam resquícios da Revolução Verde ${ }^{5}$. Só com 0 passar dos anos leva a uma interpretação acerca do "mundo rural" e suas relações com a sociedade de modo mais amplo e não apenas um olhar sobre a produtividade, contemplando outras características que permeiam 0 desenvolvimento rural.

Estas características tendem a estar vinculadas diretamente com a sustentabilidade e ao bem-estar dos indivíduos, amparando o tripé que caracteriza este conceito, incluindo as dimensões sociais, o ambientais e as econômicas.

Segundo dados do Centro Regional de Estudos para o Desenvolvimento da Sociedade da Informação - CETIC (2014), apenas 22\% dos domicílios localizados na zona rural possuem acesso à internet. Dentre os que não possuem acesso, são diversos os motivos responsabilizados, 29\% citaram o não atendimento do serviço na área habitada, $28 \%$ mencionaram a falta de habilidade por não saber utilizá-la e 51\% não a acessam devido ao custo elevado.

Diante destes aspectos, ponderando a importância de fortalecer o cenário do agronegócio nacional, em busca do desenvolvimento rural sustentável, por meio das tecnologias de informação e comunicação voltadas a sanar as necessidades da sociedade do campo, surge a seguinte problemática de pesquisa: Como o acesso às TIC utilizadas pelos Agricultores Familiares da Associação dos Bananicultores de Tupã pode auxiliar na sustentabilidade na propriedade rural?

\footnotetext{
${ }^{5}$ A Revolução Verde caracterizou-se como um paradigma tecnológico derivado da evolução dos conhecimentos da química e da biologia, que definiram uma trajetória tecnológica baseada no uso intensivo de insumos químicos (fertilizantes e pesticidas). Surgiu com o proposito de aumentar a produção agrícola. A partir de 1970, esse modelo apresentou sinais de esgotamento e severa contaminação ambiental.
} 


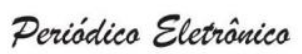 \\ Fórum Ambiental}

da Alta Paulista
Volume 11, Número 09, 2015

Produção e as

Tecnologias Sustentáveis

\section{AGRICULTURA FAMILIAR E SUSTENTABILIDADE}

As ações desencadeadas por meio das políticas públicas restabelecem as oportunidades voltadas as unidades familiares no meio rural, alavancando suas ligações com as cidades (ABROMOVAY, 1999).

Neste caso, a agricultura familiar corresponde a um seguimento do Agronegócio nacional, responsável pela maior parte da produção de alimentos in natura do consumo local e abastecimento regional das agroindústrias.

A Lei 11.326/2006 (Brasil, 2006) definiu as diretrizes oficiais para a formulação da Política Nacional da Agricultura Familiar e Empreendimentos Familiares Rurais, o que resultou em oportunidade no contexto do desenvolvimento rural e produção.

A delimitação conceitual da Agricultura Familiar, define-se em diversas óticas, dentre elas, destacam-se duas: a que configura a Agricultura Familiar em uma categoria moderna, oriunda das transformações experimentadas pelo desenvolvimento de sociedades capitalistas, e, a que se caracteriza em um conceito evolucionista, a Agricultura Familiar brasileira com raízes históricas e tradicionais. (ALTAFIN, 2007).

A evolução histórica da humanidade trouxe aos agricultores a necessidade de otimizarem seu conhecimento, partindo de uma fase extrativista com apropriação e disponibilização de recursos naturais, para um ambiente onde a informação e a capacitação são ferramentas essenciais para a manutenção da produtividade (DUARTE, 2004).

Neste contexto, destaca-se a necessidade de uma visão ampla e sistemática da interdependência dos sistemas produtivos com o uso da terra, nos quais, os desafios e complexidades devem solucionar-se por meio de um sistema sustentável (SCHENEIDER, 2008).

A sustentabilidade enquanto conceito é bastante discutida por diversos autores, no entanto, leva-se em consideração as dimensões sociais, ambientais e econômicas, das quais objetiva-se em: I) preservação do potencial da natureza para a produção de recursos renováveis; II) limitação do 
uso de recursos disponíveis; III) respeito e realce para a capacidade de autodepuração dos ecossistemas naturais (DIAS et al., 2009).

Dessa forma, os desafios encontrados nas atividades produtivas na Agricultura Familiar exigem destaque, nos quais se pode encontrar nas TIC as diretrizes para as práticas do desenvolvimento e manutenção da sustentabilidade no setor, por meio de utilização de um processo de comunicação adequado.

\subsection{COMUNICAÇÃO RURAL}

O processo de comunicação é fator fundamental no compartilhamento de informações em todas os espaços geográficos, e, no universo rural, esta importância se amplia, pois segundo Duarte (2004), a informação é requisito básico para tomar de decisões no campo, cenário onde o produtor rural deve decidir com antecedência seu planejamento de produção. Por isso as informações apresentadas ao agricultor devem ser eficientes e disponibilizadas de maneira adequada.

No caso da comunicação no meio rural, potencializam-se habilidades e atitudes peculiares para estabelecer um diálogo consistente, "no qual emissor e receptor devem estar alinhados com vocabulário, afinidades e valores, buscando a confiabilidade mútua como arcabouço necessário para se estabelecer fluxo bilateral de informações" (VIEIRA; BERNARDO; SANT'ANA, 2015, p. 9).

Neste sentido, torna-se importante observar que, como reflete Hall (1984, p.133), as relações sociais ocorridas durante o processo de comunicação envolvem não apenas emissor e receptor, mas também seus efeitos recíprocos entre os integrantes. "Quando um emissor é intimidado por seu receptor diante do processo de envio de mensagem, a própria mensagem e a interpretação dela serão afetadas".

Parte-se desta reflexão para entender o cenário do processo de comunicação no meio rural, e identificar peculiaridades e especificidades 
próprias da comunidade que integra a vida no campo. Acrescenta-se ainda a estas especificidades, a falta de acesso às novas tecnologias de comunicação e informação (TIC), ainda pouco comum no ambiente rural.

Segundo contribuições de Bernardo et al. (2015, p. 3), existe um evidente distanciamento entre os lados que estabelecem a comunicação voltada ao agronegócio. "Em algumas ocasiões chega a haver uma "incomunicação", no sentido cunhado por Bordenave (1983), acarretando uma impossibilidade de coleta de dado e condenando a pesquisa ao fracasso ou a resultados parciais"; e a ação na prática, acaba sendo pior ainda, pois a devolutiva como transferência de tecnologia também poderá ser ineficiente ou até inexistente.

O problema identificado como comunicação ineficiente, não se refere a ausência de informações, mas ao conhecimento sobre sua disponibilidade e acesso aos dados, entendimento, avaliação sobre seu potencial, além da adaptabilidade e capacidade de utilizá-la de maneira adequada, adaptada a sua realidade (DUARTE, 2004).

Com o passar dos anos, o público rural torna-se cada vez mais diversificado em idade, potencial cultural e aspectos relacionados à inclusão digital, e, complementam Bernado e Bernado (2013, p. 44) que nota-se heterogeneidade dos públicos que são abrangidos pelo agronegócio e que obrigam uma comunicação mais segmentada e, por consequência, o uso de diferentes códigos e meios. O indivíduo rural não é mais apenas o chamado "matuto" de tempos passados. "Já faz algum tempo que esse cenário vem sendo alterado e tem trazido para a comunicação uma heterogeneidade de públicos, com culturas diversas e níveis de formação muito variados".

A comunidade rural apresenta escassas oportunidades para favorecer o processo de inclusão digital, o repasse de informações e novas tecnologias voltadas a suas reais necessidades. Para Vieira; Bernardo e Sant'Ana (2015), nessa ação, a escolha do processo comunicacional adequado, minimiza ruídos e favorece a eficiência dialógica por meio de uso de tecnologias. 
Para tanto, conforme salientam Sant'Ana e Bonini Neto (2014), nota-se relevante contribuição da ciência da informação, neste procedimento de transferência de conhecimentos por meio eletrônico.

Com o advento do processo de modernização no campo e a necessidade da inclusão digital, Callou (2002, p.2), observou que essa reordenação do espaço agrário trouxe desafios sem precedentes para a comunicação rural, "na medida em que seus modelos teóricos estavam alheios aos vetores que sustentam essa espécie de difusão hi-tech ${ }^{6}$ no meio rural".

O processo de comunicação torna-se um fator desencadeador para se estabelecer um comportamento relacional de confiança no processo de compartilhamento de informações, tanto de maneira presencial como de modo eletrônico, por meio das TIC para utilização no campo.

\title{
2.2 A UTILIZAÇÃO DAS TIC NO CAMPO
}

Reforçam, Viero e Souza (2008), essa reflexão acerca da importância das TICs no meio rural ao afirmarem que:

\begin{abstract}
As últimas três décadas foram marcadas por profundas transformações no mundo rural. O produtor teve de se adequar, em um curto espaço de tempo, a uma nova realidade, onde a produção de subsistência deu lugar a um complexo sistema agroindustrial, articulando a agricultura e as zonas urbanas, a economia agrícola e a industrial. $\mathrm{O}$ conhecimento deixou de ser privilégio e tornou-se fator de desenvolvimento da agricultura. De acordo com Ripper Filho (1994), a base estratégica das nações que mais se desenvolveram no século 20 , foi a capacidade de gerar e utilizar as novas Tecnologias de Informação e Comunicação - TICs na agricultura. Através do investimento em pesquisa e em seu uso na agricultura, uma nação é capaz de avançar através de seus próprios meios e estruturas, sem depender da aquisição, mediante pagamento, de informações, processos e produtos gerados em outros locais.
\end{abstract}

Diante desse contexto, a disseminação das TICS, principalmente da internet, tornou-se também uma necessidade para o meio rural, buscando atender à demanda por informações e conhecimentos que são constantemente atualizados (VIERO; SILVEIRA, 2011)

\footnotetext{
${ }^{6}$ Alta tecnologia.
} 
As TIC podem auxiliar a desenvolver, reforçar e diversificar as atividades na zona rural, pois possibilitam o acesso a informações e assistência na atividade agrícola, dados econômicos, aproximação a novos mercados e aprimoramento do serviço a clientes, além de se tornar uma ferramenta na gestão e planejamento (MILLARD, 2000).

Tal desenvolvimento procura ter uma vertente sustentável, ao encontro da demanda dos produtores rurais, que buscam por meio das TIC, principalmente pelas facilidades oferecidas pela internet, maior comodidade para encontrar dados e informações que agreguem produtividade sustentável no meio rural com qualidade de vida.

Especificamente sobre a internet, segundo Thornton (2003), sua adoção por parte dos agricultores deve ocorrer de maneira natural, estratégica e profícua, e para que a mesma ocorra é necessário que se tenha uma infraestrutura mínima que possibilite sua conexão e que os usuários tenham o conhecimento técnico necessário à sua utilização.

Segundo Viero e Silveira (2011), a iniciativa privada não reconhece a importância da inclusão digital por parte da população rural, o que seria estratégico para o desenvolvimento econômico e permanência desta população no local, mas, expõem a ausência de políticas públicas à inclusão digital como principal responsável por tal exclusão.

Para Andrade et al. (2011) é de suma importância que a Agricultura Familiar se adapte a novas tecnologias e 0 apoio institucional na disponibilização do aprendizado tem aí um papel fundamental, sejam as instituições cooperativas, associações ou empresas de extensão.

\section{OBJETIVOS}

- Objetivo Geral:

Analisar como o acesso às TIC utilizado pelos Agricultores Familiares da Associação dos Bananicultores de Tupã pode auxiliar na sustentabilidade da propriedade rural.

- Objetivos Específicos: 
Descrever quais as TIC utilizadas pelos agricultores familiares associados;

Verificar quais são as websites acessadas na procura de informação sobre sustentabilidade para a propriedade rural.

\section{METODOLOGIA}

De caráter exploratório, por meio de um Estudo de Caso junto a Associação dos Bananicultores de Tupã, a pesquisa busca entender, esclarecer e remodelar conceitos e ideias visando à formulação de problemas mais precisos, envolvendo levantamento bibliográfico, documental. Para tanto, utilizou-se de uma pesquisa descritiva por meio de um formulário semiestruturado no qual foi aplicado por Bonfim et al. (2015) para verificar a percepção do agricultor familiar quanto questões de sustentabilidade e seu vínculo com o uso das TICs. Segundo Gil (2002), este tipo de pesquisa é realizado para identificar características de uma determinada população ou fenômeno.

Sendo um estudo de caso a aplicação do formulário foi não probabilística, e foram entrevistados 35 agricultores familiares no mês de novembro de 2014.

A análise dos resultados dos formulários foi de caráter descritivo, em sobreposição com o referencial bibliográfico.

A escolha do método de pesquisa justifica-se devido às lacunas existentes nos estudos científicos sobre a transferência de informações e tecnologias para o produtor rural, sobretudo, por meio digitais. Principalmente, voltadas para público alvo como o agricultor familiar que segundo Bordenave (1983), necessita de um processo de comunicação diferenciado do utilizado para o público urbano.

O artigo foi desenvolvido sob o viés metodológico de uma abordagem qualitativa, que buscou analisar e interpretar aspectos, hábitos e ações comportamentais sobre questões sustentáveis (MARCONI; LAKATOS, 2011). 


\section{Periódica Eletrânica

O estudo de caso único, adotado na pesquisa, caracteriza-se por ser uma análise da Associação dos Bananicultores de Tupã, voltada um público alvo que carece de receber informações específicas e desenvolver suas competências sobre sustentabilidade, com inclusão em um universo cibernético ainda hoje, pouco usual a esta classe de agricultores.

De acordo com Yin (2005) o estudo de caso, tenta esclarecer os motivos pelo qual as decisões foram tomadas, como foram implantadas e quais os resultados estabelecidos. Trata-se de um caso empírico, que investiga um fenômeno atual, dentro de um contexto de realidade.

\section{RESULTADOS}

A Associação dos Bananicultores de Tupã foi formalizada em 2004, e a priori foi composta exclusivamente por pequenos produtores da cadeia produtiva da fruticultura. Com o incremento da possibilidade de participarem das compras públicas, (Programa de Aquisição de Alimentos - PAA e Programa Nacional de Alimentação Escolar - PNAE) elevou-se o número de associados com inclusão de representantes de diversas cadeias produtivas, contando hoje com 70 núcleos familiares que fortalecem a identidade social e representam a Agricultura Familiar na microrregião de Tupã, localizada no interior paulista.

Além das reuniões mensais para trocas de informações e planejamentos futuros, os produtores rurais pertencentes à Associação de Bananicultores de Tupã criaram um grupo na Rede Social Virtual Facebook ${ }^{7}$, assim como, no aplicativo Whatsapp Messenger ${ }^{8}$, estendendo a comunicação ao ambiente tecnológico.

\footnotetext{
${ }^{7}$ Lançada em 2004 por Mark Zuckerberg, Eduardo Saverin, Chris Hughes e Dustin Moskovitz, que inicialmente foi usada para a comunicação interna dos alunos da Universidade de Harvard, e passou a ser uma das ferramentas mais acessadas mundialmente. Atualmente conta com 1.4 bilhões de usuários, e é utilizada como encontro virtual, interação social e trocas de ideias dentro de um interesse comum.

${ }^{8}$ Aplicativo de mensagens multiplataforma, que permite a troca de mensagens por meio do celular, sem cobrança de SMS, mas necessária conexão à internet. Disponível para smartphones i Phone, Android, Nokia, Windows Phone e BlackBerry.
} 


\title{
Periádica Eletrânica

Segundo Bonfim, et al. (2015), a maior parte dos 35 produtores rurais da Associação de Bananicultores de Tupã entrevistados, relataram fazer uso das TIC, sendo que:

\begin{abstract}
$43 \%$ disseram não fazer uso das TIC, outros $54 \%$ utilizam a internet. Sendo que, todos estes afirmaram usar o facebook, em especial a página da associação, e o e-mail. Identificou-se ainda que, dentre os temas de interesse, destacam-se, informações meteorológicas e cotações de produtos agrícolas. Do grupo pesquisado, $5 \%$ acessam a internet somente por smartphones, $3 \%$ informaram que conectam a internet por meio de computadores e os $46 \%$ restantes dos que relataram utilizar a internet, o fazem por meio de computadores e smartphones. Apenas 3\% não responderam ao questionário (BONFIM, et al., 2015)
\end{abstract}

Corroborando com os apontamentos de Millard (2000), os produtores rurais da Associação procuram pelas possibilidades fornecidas por meio do acesso as TIC, dos quais buscam principalmente informações sobre assuntos meteorológicos, econômicos, tecnológicos e de sustentabilidade, dentre eles, destacou-se: cotação de preços de venda de insumos e produtos agrícolas; compradores e fornecedores, programas nacionais e financiamentos, novas tecnologias para a produção, informações científicas, ambientais com enfoque para a sustentabilidade da propriedade, e por fim, cursos e oficinas online.

Tais informações foram encontradas em compartilhamentos de notícias na página da Associação no Facebook e no grupo do Whatsapp, assim como, nos sites de agronegócio (G1 - Agronegócios, Revista Globo Rural, Nosso Campo, SENAR - Serviço Nacional de Aprendizagem Rural, EMBRAPA Empresa Brasileira de Pesquisa Agropecuária), no portal do CoDAF Competências Digitais para a Agricultura Familiar e por e-mail.

Observou-se que $46 \%$ dos produtores entrevistados utilizam práticas de manejo sustentáveis isoladas, mas apenas um produtor possui o cultivo orgânico com certificação e selo chancelado pelo IBD (Instituto Biodinâmico), amparado pela legislação Lei 10.831 de 2003 regulamentada pelo Decreto 6.323 de 2007 (BRASIL, 2003; 2007). 
Outra prática sustentável identificada foi à utilização de distintivos de Inspeção Sanitárias, nas categorias: Municipal (SIM) para queijo e mel; Serviço de Inspeção Federal (SIF) para mel inspecionado por meio de entreposto associativo e um produtor detentor do selo de Inspeção Estadual (SISP) para ovos. É notável que quando a produção conquista certificação e selo de qualidade existe uma maior preocupação com o desenvolvimento sustentável da propriedade rural, nas diretrizes ambientais, sociais e econômicas.

Figura 1. Meios de busca de informação sobre sustentabilidade utilizadas pelos produtores da Associação de Bananicultores de Tupã

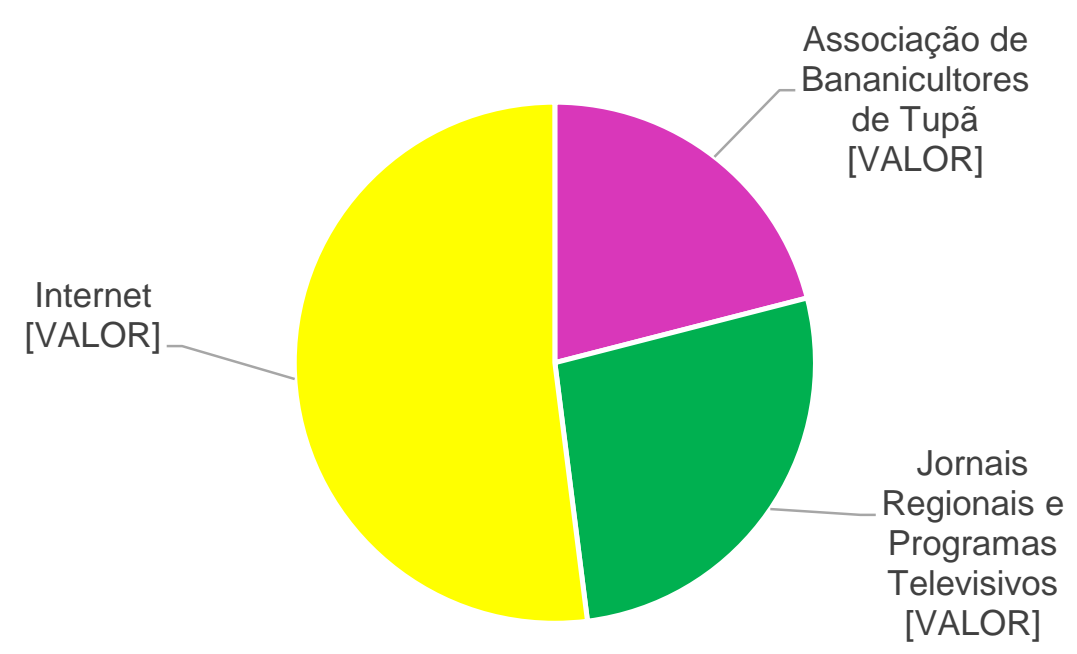

Meios de busca de Informação sobre Sustentabilidade

Fonte: Elaborado pelos autores.

Dos entrevistados, $21 \%$ relataram obter informações especificamente sobre sustentabilidade por meio da Associação de Bananicultores de Tupã, $52 \%$ revelaram conseguir as informações pela internet, já $27 \%$ recebem as informações por meio de Jornais regionais; Revistas, principalmente Globo Rural; Programas televisivos como Globo Rural, Nosso Campo e outros. O intercambio de informações com outros produtores rurais, também foi citado e enriquece os resultados desta pesquisa.

Diante destes aspectos, o acesso as TIC mostraram-se o meio mais utilizado na busca de informação sobre sustentabilidade. Em tempos de 


\section{Periódica Eletrânica

globalização, a internet permite que o ambiente virtual além da informação, proporcione locais de debates e trocas simultâneas, nos quais enriquecem o conhecimento dos produtores da Agricultura Familiar carentes de instruções e inclusão digital, em busca do desenvolvimento rural sustentável.

\section{CONCLUSÃO}

Nota-se que alguns fatores ainda dificultam o acesso dos produtores as TIC, e a falta de habilidade com as novas tecnologias ganha destaque entre essas barreiras.

Embora as TIC não sejam utilizadas pela totalidade dos produtores, 54\% dos produtores rurais que adotaram as TIC compreendem a importância do seu uso como recurso de apoio a gestão e comunicação dentro do setor rural, de modo que, o acesso as TIC configura-se como fator importante na tomada de decisões, proporcionando um apoio concomitante no desenvolvimento sustentável da propriedade rural, mostrando-se como um caminho para

\section{REFERÊNCIAS BIBLIOGRÁFICAS}

ABRAMOVAY, R. Agricultura familiar e desenvolvimento territorial,1999. Disponível em:< http://www.fea.usp.br/feaecon//media/fck/File/Agricultura_familiar.pdf >. Acesso em 10 set. 2015.

ANDRADE, A.L.S; GONTIJO, C.M; FRANÇA, P.B. Gestão do Agronegócio familiar: estudo de caso da fazenda Paraíso. Revista Brasileira de Gestão e Engenharia. São Gotardo n.3, jan./jun. 2011.

ALTAFIN, I. Reflexões sobre o conceito de agricultura familiar. Texto trabalhado durante 0 3 o Módulo do Curso Regional de Formação Político-sindical da região Nordeste/2007.

Disponível em

< http://mstemdados.org/sites/default/files/Reflex\%C3\%B5es\%20sobre\%20o\%20conceito\%20d e\%20agricultura\%20familiar\%20-\%20lara\%20Altafin\%20-\%202007_0.pdf > Acesso em 10 set. 2015.

BERNARDO, C.H.C.; BERNARDO, R. Gestão da Comunicação para o agronegócio. Revista Cambiassu. UFMA, n.12, p. 43-55, jan/jun. 2013.

BERNARDO, C. H. C.; VIEIRA, S. C.; LOURENZANI, A. E. B. S.; SATOLO, E. G. O papel do extensionista na sociedade atual: ultrapassando as barreiras de comunicação. 53ํㅡ Congresso da Sociedade Brasileira de Economia, Administração e Sociologia Rural. João 


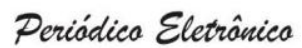

Pessoa. 2015. v. 1, p. 1-18, 2015. Disponível em <http://icongresso.itarget.com.br/tra/arquivos/ser.5/1/4931.pdf> Acesso em 13 set. 2015.

BONFIM, E. B; SANT'ANA, R. C.; BERNARDES, J. C.; PEREIRA, M. E. B. G.; VIEIRA, S. C. Análise das TIC acessadas por produtores rurais familiares da Associação de Bananicultores de Tupã/SP. XVII Congresso de Iniciação Científica UNESP. 2015. Disponível em: $<$

http://prope.unesp.br/cic/adm/ver_resumo.php?area $=100083 \&$ subarea $=25248 \&$ congresso $=37 \&$ $\mathrm{CPF}=40470538805>$. Acesso em 22 set. 2015.

BORDENAVE, J. D. O que é comunicação rural. 3. ed. São Paulo: Editora Brasiliense, 1983.

BRASIL. Lei no 10.831 de 23 de dezembro de 2003. Disponível em < http://www.planalto.gov.br/ccivil_03/leis/2003/L10.831.htm>. Acesso em 23 set. 2015.

Decreto no 6.323, de 27 de dezembro de 2007. Disponível em < http://www.planalto.gov.br/ccivil_03/_ato2007-2010/2007/Decreto/D6323.htm>. Acesso em 23 set. 2015.

CALLOU, A. B. F. Comunicação rural e era tecnológica: tema de abertura. Comunicação rural, tecnologia e desenvolvimento local. Recife: Bagaço, p. 07-28, 2002. Disponível em < http://www.portcom.intercom.org.br/pdfs/e2fa822dc6555d735799b5efe02f8f2e.PDF>. Acesso em 18 set. 2015.

CETIC - Centro Regional de Estudos para o Desenvolvimento da Sociedade da Informação. Disponível em:< http://data.cetic.br/cetic/explore?idPesquisa=TIC_DOM>. Acesso em 22 set. 2015.

DIAS, P. F. M.; SANTOS JÚNIOR, S.; ROSA, P. N.; MENDONÇA, E. Análise da Sustentabilidade da Produção de Biodiesel de Soja no Brasil. Revista de Administração, Frederico Westphalen/RS, v.8, n.14, p. 13 - 45, 2009. Disponível em file:///D:/Downloads/9093873-1-PB.pdf. Acesso em 08 set. 2015.

DUARTE, J. A. M. Comunicação e Tecnologia na cadeia produtiva da soja em MT. Tese do Curso de Pós Graduação em Comunicação Social. São Bernardo do Campo SP: Universidade Metodista de São Paulo, 2004. Disponível em $<$ http://ibict.metodista.br/tedeSimplificado/tde_busca/arquivo.php?codArquivo=45 > Acesso em 09 set. 2015.

GIL, Antonio Carlos. Como elaborar projetos de pesquisa. São Paulo: Atlas, 2002.

MARCONI, M. A.; LAKATOS, E. M;Metodologia científica. 6 ed. São Paulo: Atlas, 2011

MILLARD, J. L. Cadernos do Observatório. As tecnologias de informação a serviço do desenvolvimento rural. nำ, 2000. 52 p. 2000.

SANT'ANA, R.C.G.; BONINI NETO, A. Análise de dados sobre produção de leite: uma perspectiva da Ciência da Informação. Informação e Tecnologia. V.1,Num.1, jan/jun, 2014. Disponível em < http://www.ies.ufpb.br/ojs2/index.php/itec/article/view/19493/10863>. Acesso em 12 set. 2015.

SCHENEIDER, P. C. Agricultura Familiar e Empreendedorismo: um estudo sobre as trajetórias de jovens egressos do centro de desenvolvimento do Jovem Rural do (CEDEJOR) no Vale do Rio Pardo/RS. 2008. 193f. Dissertação (Desenvolvimento Rural) UFRGS, Porto Alegre, 2008. 
THORNTON, R. El agricultor, Internet y las barreras a su adopción. In: THORNTON, R.;CIMADEVILLA, G. (Ed.). La extensión rural en debate: concepciones, retrospectivas, cambios y estratégias para el Mercosur. Buenos Aires: Inta, 2003. p. 323-344.

VIEIRA, S. C.; BERNARDO, C. H.C.; SANT'ANA, R. C. G.. A relevância da comunicação rural na difusão de informações para a agricultura familiar: um estudo de caso do CoDAF. Em: XI Fórum Ambiental da Alta Paulista, 2015. (No prelo).

VIERO, Veronica Crestani; SOUZA, Renato Santos De. Comunicação rural on-line: promessa de um mundo sem fronteiras. In: 46th Congress, July 20-23, 2008, Rio Branco, Acre, Brasil. Sociedade Brasileira de Economia, Administracao e Sociologia Rural (SOBER), 2008.

VIERO, V. C., SILVEIRA, A. C. Apropriação de tecnologias de informação e comunicação no meio rural brasileiro. Cadernos de Ciência \& Tecnologia, v.28, n.1, p.257-277, 2011.

YIN, R. K. Estudo de caso: planejamento e métodos. 3. ed. Porto Alegre: Bookman, 2005. 212p. 